\title{
Development of Sensor with High Selectivity for Saltiness and Its Application in Taste Evaluation of Table Salt
}

\author{
Ronggang Chen ${ }^{1,2, *}$, Ikezaki Hidekazu ${ }^{1}$ and Kiyoshi Toko \\ 'Intelligent Sensor Technology, Inc., \\ 5-1-1 Onna, Atsugi-shi, Kanagawa 243-0032, Japan \\ ${ }^{2}$ Information Science and Electrical Engineering, Kyushu University, \\ 744 Motooka, Nishi-ku, Fukuoka 819-0395, Japan
}

(Received September 17, 2009; accepted December 25, 2009)

Key words: saltiness sensor, saltiness, bitterness, charge density

Previous research has focused on using taste sensors to evaluate very low concentrations of minerals in table salt that cannot be detected with the senses, indicating potential applications in salt quality control. However, the poor selectivity of taste sensors for salt and the inability to evaluate the total taste due to the presence of other tastes, such as bitterness, besides saltiness have become new research topics. Our work aims to improve the selectivity of sensors for saltiness by optimizing the sensor components for foodstuff applications. Furthermore, we have evaluated saltiness with a high correlation to human sensory saltiness evaluation scores by a new analysis method using saltiness sensors with positively and negatively charged membranes. We hope that the optimized saltiness sensors and new analysis method can be used in evaluating the taste of salt in the general foodstuff industry.

\section{Introduction}

The general foodstuff industry uses table salt from both domestic and overseas producers; the contents of chemicals, including $\mathrm{NaCl}, \mathrm{MgCl}_{2}, \mathrm{CaSO}_{4}$, and $\mathrm{KCl}$, in salt vary according to the production method, causing large differences in taste. Since $\mathrm{MgCl}_{2}, \mathrm{CaCl}_{2}$, and $\mathrm{KCl}$, have bitter and salty tastes, solutions with high levels of these chemicals are called nigari in Japan. ${ }^{(1)}$ We have reported a previous work on evaluating trace concentrations of nigari components, such as $\mathrm{MgCl}_{2}$ and $\mathrm{CaCl}_{2}$, in table salt with good reproducibility and possible applications to food quality control. ${ }^{(2,3)}$

Previous research has used adsorption data from artificial lipid-membrane sensors similar to those used to evaluate hydrophobic bitter materials, such as quinine hydrochloride, to evaluate $\mathrm{Mg}^{2+}$ and $\mathrm{Ca}^{2+}$ ions in nigari components. Owing to the high selectivity of the sensor for $\mathrm{Mg}^{2+}$ and $\mathrm{Ca}^{2+}$, trace concentrations can be detected ${ }^{*}$ Corresponding author: e-mail: chin.eigou@insent.co.jp 
with a high sensitivity at any $\mathrm{NaCl}$ concentration. ${ }^{(2,3)}$ However, it is commonly observed that bitterness cannot be tasted in salt solutions containing trace amounts of bitter components. Consequently, we consider that bitterness is suppressed either by a certain form of interaction between the nigari components and $\mathrm{NaCl}$, or between the nigari components, $\mathrm{NaCl}$, and the bitterness receptors in the human tongue. Strongly hydrophobic materials, such as quinine hydrochloride, are considered to be adsorbed onto the sensor lipid membrane, changing the membrane potential, but metallic ions, such as $\mathrm{Mg}^{2+}$ and $\mathrm{Ca}^{2+}$, are thought to react through a certain mechanism other than adsorption. As a consequence, current saltiness sensors have difficulty evaluating the tastes of salty foodstuffs that include bitterness caused by nigari components.

The current work investigates how to improve selectivity for saltiness by optimizing the sensor components. We measured various salty materials focusing on their anion and cation structures using sensors with positively and negatively charged membranes with a high selectivity for saltiness, and evaluated the strength of and qualitative differences in saltiness. In addition, we measured samples including nigari components using sensors with positively and negatively charged membranes, and estimated the vertical distance between the response curves and the $\mathrm{NaCl}$ curve as an index of bitterness. The results suggest that it is possible to evaluate the tastes of both the $\mathrm{NaCl}$ and nigari components in table salt. Furthermore, the analysis results obtained with the saltiness sensors closely approximated the results of human sensory evaluation scores for salty materials, suggesting that these sensors can be used to accurately assess the saltiness of various foodstuffs.

\section{Materials and Methods}

\section{$2.1 \quad$ Measurement setup}

Measurements were performed using the TS-5000Z Taste Sensing System of Intelligent Sensor Technology Inc., Japan. The system is composed of a sensor unit and a management server computer. Up to 8 sensors can be connected to the unit. Figure 1 shows a diagram of the taste sensor and taste-sensing system. The sensor surface is composed of an attached artificial lipid membrane containing an artificial lipid that responds to basic tastes plus a plasticizer. This artificial lipid membrane reacts with taste substances based on electrostatic and hydrophobic interactions, and the electric potential of the lipid membrane changes in the same way as that of the taste receptors of living organisms. This potential change is detected as the sensor output and evaluated as taste information by the computer. ${ }^{(4-6)} \mathrm{A} \mathrm{Ag} / \mathrm{AgCl}$ electrode including a saturated solution of $\mathrm{KCl}$ was used as the reference electrode. A solution of $3.3 \mathrm{M} \mathrm{KCl}$ and saturated $\mathrm{AgCl}$ was used as the inner solution of the lipid-membrane sensor and reference electrode. Before measurement, these electrodes were preconditioned for 2 days in a reference solution containing $30 \mathrm{mM} \mathrm{KCl}$ and $0.3 \mathrm{mM}$ tartaric acid. Table 1 shows the components of the taste sensors used in this work. Since the lipid membrane was either positively or negatively charged depending on the lipid type, we describe the sensors as either positively or negatively charged membrane sensors in this paper. 


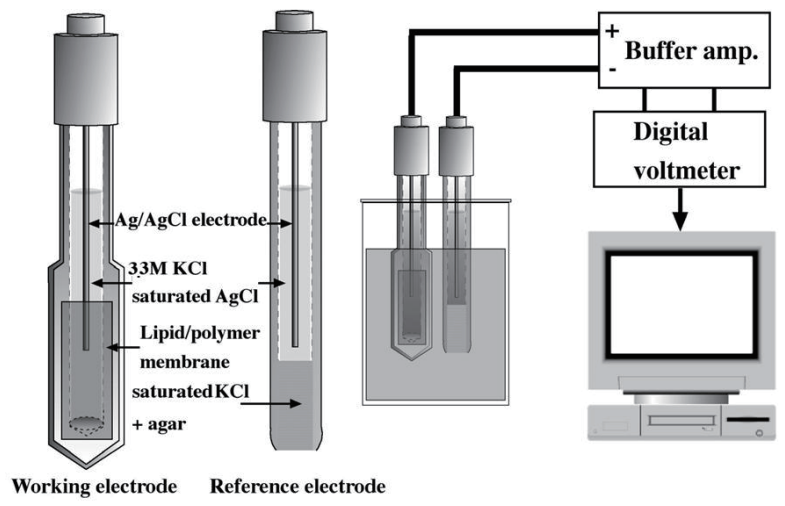

Fig. 1. Diagram of taste sensor and taste-sensing system.

Table 1

Components of lipid membrane.

\begin{tabular}{cllc}
\hline Ch. & \multicolumn{1}{c}{ Lipid } & \multicolumn{1}{c}{ Plasticizer } & Charge \\
\hline 1 & phosphoric acid di- $n$-decyl ester (PADE) & $1000 \mu \mathrm{ldi}-n$-octyl phenylphosphonate (DOPP) & negative \\
2 & sodium hexadecyl sulfate (SHS) & $1000 \mu \mathrm{l}$ bis(1-butylpentyl) adipate (BBPA) & negative \\
& $400 \mathrm{mg}$ tetradodecyl ammonium bromide & $3850 \mathrm{mg}$ di- $n$-octyl phenylphosphonate & positive \\
& $315 \mathrm{mg}$ 1-hexadecanol & $(\mathrm{DOPP})$ & \\
\hline
\end{tabular}

\subsection{Test methods and samples}

\subsubsection{Measurement method}

The reference solution was measured first $\left(V_{\mathrm{r}}\right)$ before measuring the sample $\left(V_{\mathrm{s}}\right)$ and $V_{\mathrm{s}}-V_{\mathrm{r}}$ was used as the sensor output.

\subsubsection{Evaluating saltiness selectivity of saltiness sensor}

Table 2 shows the five representative taste sample materials measured to evaluate the sensor selectivity.

\subsubsection{Taste evaluation of salty materials}

To evaluate the concentration dependence of various salty materials, solutions of $\mathrm{NaCl}, \mathrm{KCl}, \mathrm{MgCl}_{2}, \mathrm{CaCl}_{2}, \mathrm{Na}_{2} \mathrm{SO}_{4}$, and $\mathrm{NaH}_{2} \mathrm{PO}_{4}$ at different concentrations shown in Table 3 were measured. In addition, to investigate the bitterness of nigari components, the $\mathrm{NaCl}, \mathrm{KCl}, \mathrm{MgCl}_{2}$, and $\mathrm{CaCl}_{2}$ mixtures listed in Table 4 were measured.

\subsubsection{Sensory score evaluation}

As mentioned previously, the nigari components of the salty materials, such as $\mathrm{KCl}$, $\mathrm{MgCl}_{2}$ and $\mathrm{CaCl}_{2}$, are both salty and bitter tasting. Moreover, the bitter taste of these nigari components varies greatly depending on the $\mathrm{NaCl}$ concentration. To evaluate the saltiness of materials including these nigari components, panels of two healthy 
Table 2

Components of sample solutions for basic tastes.

\begin{tabular}{ll}
\hline Sample & Components \\
\hline Reference solution & $30 \mathrm{mM} \mathrm{KCl}+0.3 \mathrm{mM}$ tartaric acid \\
Salty sample & $300 \mathrm{mM} \mathrm{KCl}+0.3 \mathrm{mM}$ tartaric acid \\
Sour sample & $30 \mathrm{mM} \mathrm{KCl}+3 \mathrm{mM}$ tartaric acid \\
Umami (savoriness) sample & $30 \mathrm{mM} \mathrm{KCl}+0.3 \mathrm{mM}$ tartaric acid \\
& $+10 \mathrm{mM} \mathrm{sodium} \mathrm{hydrogen} \mathrm{L-glutamate} \mathrm{monohydrate}$ \\
Bitter sample (cation) & $30 \mathrm{mM} \mathrm{KCl}+0.3 \mathrm{mM}$ tartaric acid $+0.1 \mathrm{mM}$ quinine hydrochloride \\
Bitter sample (anion) & $30 \mathrm{mM} \mathrm{KCl}+0.3 \mathrm{mM}$ tartaric acid $+0.01 \mathrm{vol} \%$ humulone derivatives \\
Astringent sample & $30 \mathrm{mM} \mathrm{KCl}+0.3 \mathrm{mM}$ tartaric acid $+0.05 \mathrm{wt} \%$ tannic acid \\
\hline
\end{tabular}

Table 3

Samples for saltiness evaluation.

\begin{tabular}{ll}
\hline Sample* & Components \\
\hline Samples 1-8 & $0,1,3,10,30,100,300,1000 \mathrm{mM} \mathrm{NaCl}$ \\
Samples 9-16 & $0,1,3,10,30,100,300,1000 \mathrm{mM} \mathrm{KCl}$ \\
Samples 17-21 & $0,0.3,1,3,10 \mathrm{mM} \mathrm{MgCl}_{2}$ \\
Samples 22-26 & $0,0.3,1,3,10 \mathrm{mM} \mathrm{CaCl}_{2}$ \\
Samples 27-32 & $0,1,3,10,30,100 \mathrm{mM} \mathrm{Na}_{2} \mathrm{SO}_{4}$ \\
Samples 33-38 & $0,1,3,10,30,100 \mathrm{mM} \mathrm{NaH}_{2} \mathrm{PO}_{4}$ \\
\hline
\end{tabular}

*All samples included $1 \mathrm{mM} \mathrm{KCl}$ as the supporting electrolyte.

Table 4

Salty materials in samples.

\begin{tabular}{|c|c|c|}
\hline \multirow{2}{*}{ Sample ${ }^{* 1}$} & \multicolumn{2}{|r|}{ Components $^{* 2}$} \\
\hline & Component A & Component B \\
\hline Samples 1-3 & $0 \mathrm{mM} \mathrm{NaCl}$ & $10 \mathrm{mM} \mathrm{KCl}, 10 \mathrm{mM} \mathrm{MgCl}_{2}, 10 \mathrm{mM} \mathrm{CaCl}_{2}$ \\
\hline Samples 4-6 & $1 \mathrm{mM} \mathrm{NaCl}$ & $10 \mathrm{mM} \mathrm{KCl}, 10 \mathrm{mM} \mathrm{MgCl}_{2}, 10 \mathrm{mM} \mathrm{CaCl}_{2}$ \\
\hline Samples 7-9 & $3 \mathrm{mM} \mathrm{NaCl}$ & $10 \mathrm{mM} \mathrm{KCl}, 10 \mathrm{mM} \mathrm{MgCl}_{2}, 10 \mathrm{mM} \mathrm{CaCl}_{2}$ \\
\hline Samples 10-12 & $10 \mathrm{mM} \mathrm{NaCl}$ & $10 \mathrm{mM} \mathrm{KCl}, 10 \mathrm{mM} \mathrm{MgCl}_{2}, 10 \mathrm{mM} \mathrm{CaCl}_{2}$ \\
\hline Samples 13-15 & $30 \mathrm{mM} \mathrm{NaCl}$ & $10 \mathrm{mM} \mathrm{KCl}, 10 \mathrm{mM} \mathrm{MgCl}_{2}, 10 \mathrm{mM} \mathrm{CaCl}_{2}$ \\
\hline Samples $16-18$ & $100 \mathrm{mM} \mathrm{NaCl}$ & $10 \mathrm{mM} \mathrm{KCl}, 10 \mathrm{mM} \mathrm{MgCl}, 10 \mathrm{mM} \mathrm{CaCl}_{2}$ \\
\hline
\end{tabular}

${ }^{* 1}$ All samples included $1 \mathrm{mM} \mathrm{KCl}$ as the supporting electrolyte.

${ }^{*}$ All samples were composed of two types of salty material (components A and B). For example, Sample 1 was $[0 \mathrm{mM} \mathrm{NaCl}+10 \mathrm{mM} \mathrm{KCl}]$ and Sample 2 was $\left[0 \mathrm{mM} \mathrm{NaCl}+10 \mathrm{mM} \mathrm{MgCl}_{2}\right]$.

women and two healthy men evaluated the nine samples listed in Table 5 to correlate the taste of nigari components, such as $\mathrm{NaCl}, \mathrm{KCl}, \mathrm{MgCl}_{2}$, and $\mathrm{CaCl}_{2}$, with changes in the strength of the bitter taste between nigari components. Each panel of tasters evaluated the strength of the bitter taste by holding a sample in the mouth for $10 \mathrm{~s}$. To simplify evaluation of differences between samples, each test was performed once by each group. Furthermore, six sample combinations were selected to test for differences in the strength of the bitter taste of the nigari components as well as the correlation between $\mathrm{NaCl}$ and 
Table 5

Components of sensory score evaluation samples.

\begin{tabular}{cl}
\hline Sample & \multicolumn{1}{c}{ Components } \\
\hline 1 & $10 \mathrm{mM} \mathrm{KCl}$ \\
2 & $10 \mathrm{mM} \mathrm{KCl}+10 \mathrm{mM} \mathrm{NaCl}$ \\
3 & $10 \mathrm{mM} \mathrm{KCl}+100 \mathrm{mM} \mathrm{NaCl}$ \\
4 & $10 \mathrm{mM} \mathrm{MgCl}_{2}$ \\
5 & $10 \mathrm{mM} \mathrm{MgCl}_{2}+10 \mathrm{mM} \mathrm{NaCl}$ \\
6 & $10 \mathrm{mM} \mathrm{MgCl}_{2}+100 \mathrm{mM} \mathrm{NaCl}$ \\
7 & $10 \mathrm{mM} \mathrm{CaCl}_{2}$ \\
8 & $10 \mathrm{mM} \mathrm{CaCl}_{2}+10 \mathrm{mM} \mathrm{NaCl}$ \\
9 & $10 \mathrm{mM} \mathrm{CaCl}_{2}+100 \mathrm{mM} \mathrm{NaCl}$ \\
\hline
\end{tabular}

the strength of the bitter taste of the nigari components by performing six rounds of sensory evaluation tests, as shown in Fig. 11. Tasters rinsed their mouths between tests. The bitterness score (bitterness strength) was ranked on a scale of 3 with 3 being the most bitter and 1 being not bitter at all.

\section{Results and Discussion}

\subsection{Optimizing plasticizers and lipids}

Previously described saltiness sensors have been composed of the plasticizer di- $n$ octyl phenylphosphonate (DOPP) and the artificial lipid phosphoric acid di- $n$-decyl ester (PADE); Fig. 2(a) shows the molecular structure. Since they are negatively charged, they respond to cations, such as $\mathrm{Na}^{+}$and $\mathrm{K}^{+} .(2,3)$ However, obtaining a response to acidic and salty bitter materials indicates a low selectivity for salt, creating problems with achieving a high-accuracy method of evaluating the taste of salt in actual daily foodstuffs. Consequently, this work focused on optimizing the components of a saltiness sensor that would not be affected by either sour or bitter materials.

The response to sour materials depends on changes in $\mathrm{pH}$, which cause changes in the levels of dissociation of PADE and impurities (such as monoester phosphate) ${ }^{(6)}$ in the commercial DOPP plasticizer used in lipid membranes. Consequently, we must select an artificial lipid and a plasticizer that do not dissociate in the $\mathrm{pH}$ range of general foodstuffs from 2 to 8 . As a result, we used bis(1-butylpentyl) adipate (BBPA) as a new plasticizer with no monoester impurities. To evaluate the plasticizer response to basic tastes, we fabricated a sensor composed of BBPA plasticizer without artificial lipids and measured the samples listed in Table 2. The results are shown in Fig. 3. For comparison, the same measurements were performed using a DOPP-only membrane sensor.

Figure 3 shows that the DOPP-membrane sensor is more responsive to sour samples than salty samples, whereas the BBPA-membrane sensor is more responsive to salty samples than sour samples. From these results, BBPA is clearly considered to be a better plasticizer for a saltiness sensor than DOPP.

However, Fig. 3 shows that the DOPP- and BBPA-membrane sensors have about the same high response to the bitter sample (cation), suggesting that the saltiness selectivity 


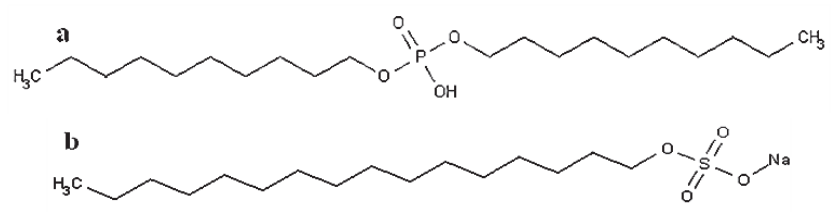

Fig. 2. Molecular structures of PADE and SHS: (a): PADE and (b): SHS.

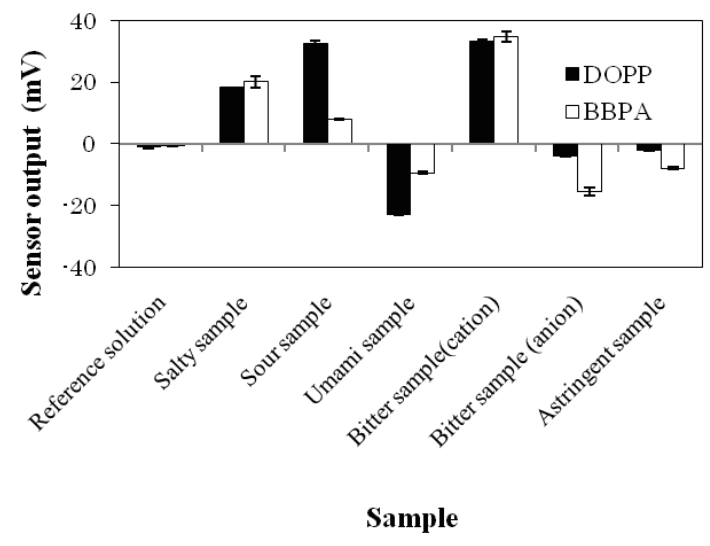

Fig. 3. Responses of sensors with different plasticizers to the sample solutions for basic tastes.

of these sensors might be affected by bitter materials. Sensitivity and selectivity to bitter materials are based greatly on the charge density of taste sensors, depending on the degree of lipid incorporation into the membrane. ${ }^{(8,9)}$ At higher lipid concentration in the membrane, even if the bitter substance adsorbs on the membrane and then causes a decrease in the charge density, it cannot cause change in the membrane potential owing to the extremely high density of the membrane. This finding suggests that the sensor with higher charge density has lower sensitivity to bitter materials, consequently leading to higher selectivity to salty substances. Therefore, to reduce the impact of both the presence of bitter samples (cation) and the changes in the $\mathrm{pH}$ of samples, we need to fabricate a negatively charged lipid membrane with a high charge density. To meet this need, we fabricated different sensors consisting of different amounts of the lipid "sodium hexadecyl sulfate (SHS)," which has a higher dissociation than the lipid PADE, and the BBPA plasticizer (molecular structure shown in Fig. 2(b)). For comparison, sensors were also fabricated with different amounts of PADE and the plasticizer BBPA. These sensors with the two types of lipid were measured with the samples listed in Table 2. The test results are shown in Fig. 4.

Figure 4(a) shows that the sensitivity to salty samples increases as PADE content increases, but the sensitivity to other bitter samples (cation), which affects salt sensitivity, also increases. Conversely, Fig. 4(b) shows that the sensitivity to salty samples increases as the amount of SHS increases, but the sensitivity to other samples is almost zero. From 

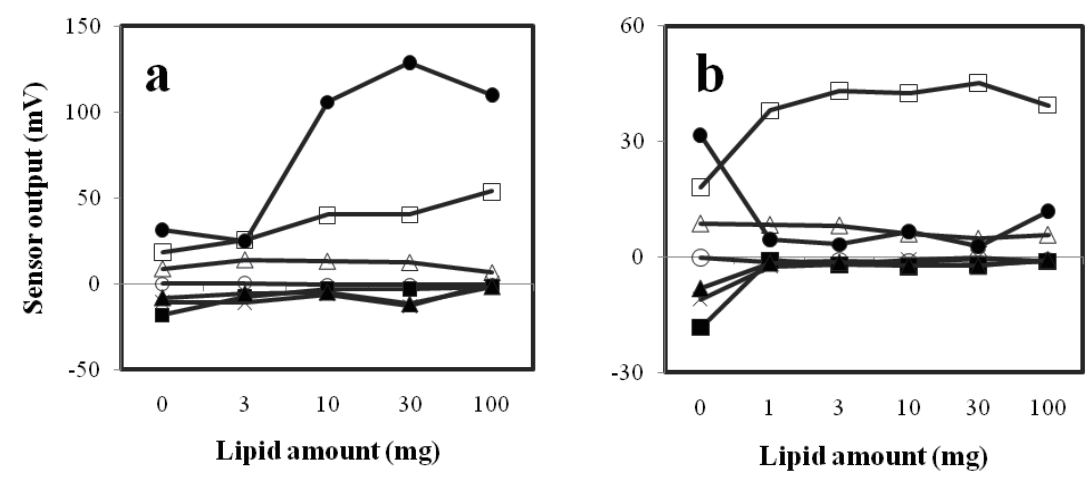

Fig. 4. Responses of sensors with different lipids to the sample solutions for basic tastes: (a): PADE and (b): SHS ( $\bigcirc$ : reference sample; $\square$ : salty sample; $\triangle$ : sour sample; $\times$ : umami sample; • bitter sample (cation); $\mathbf{m}$ : bitter sample (anion); $\mathbf{\Delta}$ : astringent sample).

these results, the sensor membrane composed of the BBPA plasticizer and SHS lipid is considered to be greatly improved in terms of the selectivity for salty materials.

These results are explained by the dissociation and hydrophobicity of the lipid. Figure 5 shows the effect of $\mathrm{pH}$ on the ion fraction ratio of SHS and PADE in a solution using "Marvin Sketch," which is a chemistry software designed by ChemAxon Corp, Hungary. Marvin Sketch can calculate the microspecies ratio of all proton gaining or losing atoms on the basis of the partial charge in distribution, and the octanol/water partition coefficient. This result indicates that while SHS is mostly dissociated in the range of $\mathrm{pH}$ from 0 to 8 , PADE increases the level of dissociation in the range of $\mathrm{pH}$ from 0 to 4 as $\mathrm{pH}$ increases, indicating that SHS is practically unaffected by $\mathrm{pH}$ changes in the range of $\mathrm{pH}$ from 0 to 8 . In contrast, $\mathrm{PADE}$ is affected in the range of $\mathrm{pH}$ from 0 to 4 . The difference in the two molecules in terms of response to $\mathrm{pH}$ is because the SHS has the sulfonate group, which dissociates completely in an aqueous solution, while the PADE contains the phosphate group, which dissociates partially in an aqueous solution. Dissociation in a solution and dissociation in a membrane are expected to be naturally different, but the calculation results show that the effect is clear, as shown in Fig. 5. For these reasons, SHS is better at suppressing the effect of $\mathrm{pH}$ than PADE.

Next, we used Marvin Sketch to calculate $\log P$ as an index of the hydrophobicity of the artificial lipids. The results of 3.82 for SHS and 6.2 for PADE show that SHS has higher hydrophilicity in a solution at $\mathrm{pH}$ 3.5. From these results, we consider that SHS forms a hydrophilic membrane surface more easily owing to self-organization in an aqueous solution. On the basis of this observation, we assume that increasing the hydrophilicity of the SHS sensor membrane surface suppresses the adsorption of hydrophobic materials, such as the bitter sample.

However, because SHS is more hydrophilic than PADE, there is a possibility of a slight dissolution of SHS during measurement causing variations in sensitivity. As 


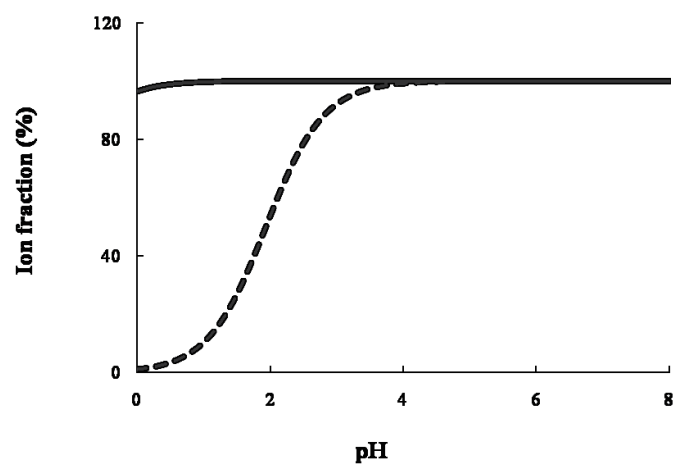

Fig. 5. Ion fraction of the lipids in the membrane in solution with change in $\mathrm{pH}$ (curve: SHS ions; broken line: PADE; calculated using Marvin Sketch).

shown in Fig. 4(b), when SHS is $3 \mathrm{mg}$ or less, a decrease in saltiness sensitivity can be expected; thus, the optimum SHS content is $30 \mathrm{mg}$. In the rest of this paper, this sensor is described as a "negatively charged saltiness sensor."

\subsection{Identifying salty materials using new analysis methods for sensitivity of} positively and negatively charged saltiness sensors

Salty materials have both anion and cation structures, and their tastes are considered to be determined by the combination of these two ion types. We investigated the taste evaluation of salty materials using two sensors with a high selectivity for anionic and cationic salty materials. To evaluate cations, we used the negatively charged saltiness sensor fabricated as described in $\S 3.1$; anions were evaluated as described in Table 1 of $\S 3$, where a saltiness sensor with a fixed positively charged lipid is described from hereon as a "positively charged saltiness sensor." Figure 6 shows the response of this sensor to the basic tastes in Table 2. From Fig. 6 it is clear that the positively charged saltiness sensor responds only to the salty sample and has both high sensitivity and high selectivity for anionic salty materials.

We measured the samples listed in Table 3 to evaluate the dependence of these two sensors on the concentration of each salty material. The results in Fig. 7 indicate that the negatively charged saltiness sensor responds equally to the $\mathrm{Na}^{+}$ions in the different salty materials, but its response to other cations varies. This observation suggests that this sensor can identify cations and is highly sensitive to $\mathrm{Ca}^{2+}, \mathrm{Mg}^{2+}, \mathrm{K}^{+}$, and $\mathrm{Na}^{+}$in this order. It is well known that the ion exchange resin with sulfonic acid responds to cations in the following order: $\mathrm{Ca}>\mathrm{Mg}>\mathrm{K}>\mathrm{Na}>\mathrm{H}$. This implies that the response of this negatively charged saltiness sensor may be similar to that of the ion exchange resin. This is thought to be due to differences in ion radius and electronegativity between cations and ions, although we are still not absolutely sure. ${ }^{(10,11)}$ In the same way, Fig. 7(b) shows that the positively charged saltiness sensor responds equally to the $\mathrm{Cl}^{-}$ions in the different salty materials, but its response to other anions varies. This observation suggests that this sensor can discriminate between different anion types. 


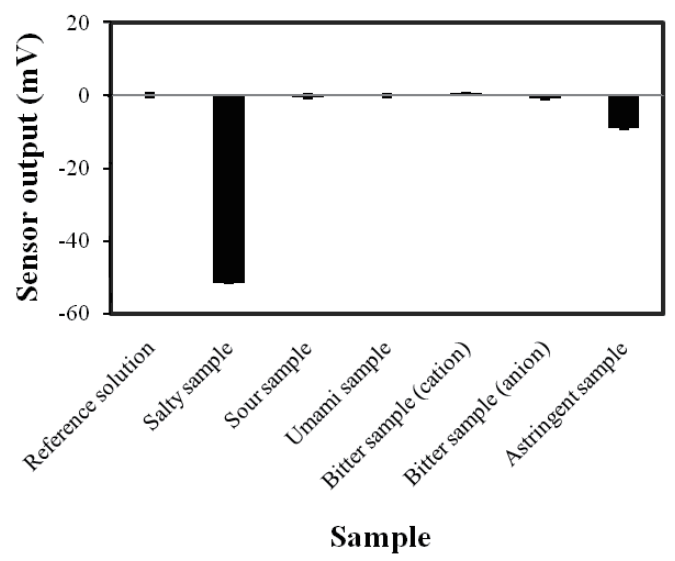

Fig. 6. Response of positively charged saltiness sensor to the sample solutions for basic tastes.

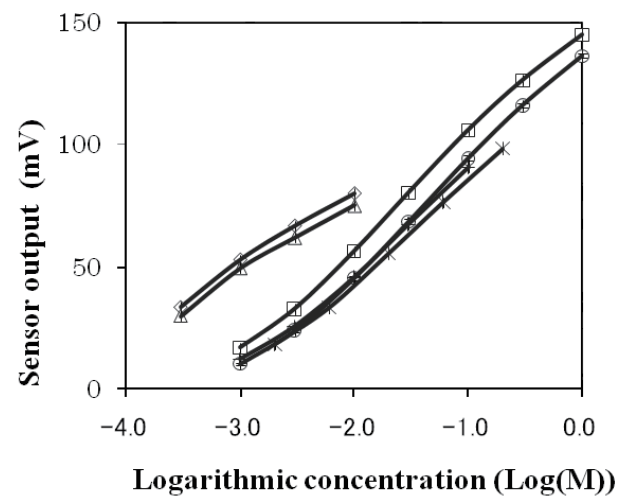

(a)

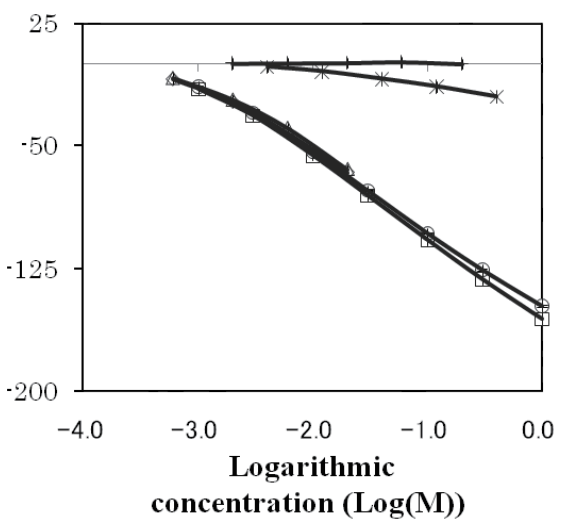

(b)

Fig. 7. Concentration dependence of responses of the saltiness sensors to salty materials: $\bigcirc: \mathrm{NaCl}$; $\square: \mathrm{KCl} ; \triangle: \mathrm{MgCl}_{2} ; \diamond: \mathrm{CaCl}_{2} ; \times: \mathrm{Na}_{2} \mathrm{SO}_{4} ;+$ : $\mathrm{NaH}_{2} \mathrm{PO}_{4}$ (left: negatively charged saltiness sensor; right: positively charged saltiness sensor).

Figure 7(b) shows that this positively charged saltiness sensor can also be used to evaluate samples containing $\mathrm{SO}_{4}{ }^{2-}$ and $\mathrm{PO}_{4}{ }^{3-}$ ions, but considering the components of currently marketed table salt and comparing $\mathrm{SO}_{4}{ }^{2-}$ and $\mathrm{PO}_{4}{ }^{3-}$ with $\mathrm{Cl}^{-}$, since the number of the former ions is much smaller than that of the latter ions, it seems most probable that the $\mathrm{Cl}^{-}$anions have the greatest impact on the actual saltiness of table salt. As a result, we limited the measured salty materials in the examined samples to $\mathrm{NaCl}, \mathrm{KCl}$, $\mathrm{MgCl}_{2}$, and $\mathrm{CaCl}_{2}$. In addition, to simplify the observation of the two-dimensional data for anions and cations, the sensitivity data for the two types of sensor obtained from the results presented in Fig. 7 were plotted as a 2D scatter plot (Fig. 8). In this figure, the 


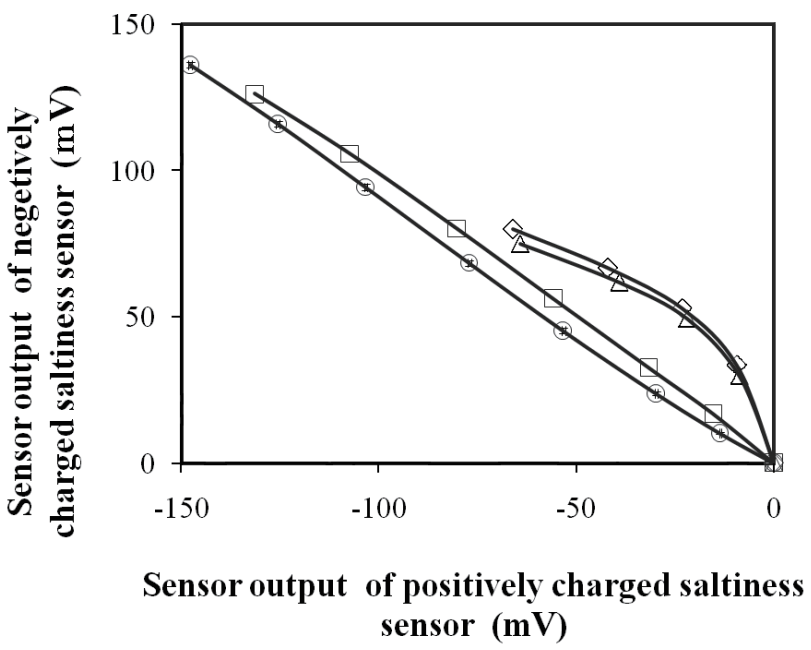

Fig. 8. Scatter plot of responses of positively and negatively charged saltiness sensors to anions and cations of salty materials: $\bigcirc: \mathrm{NaCl} ; \square: \mathrm{KCl} ; \triangle: \mathrm{MgCl}_{2} ; \diamond: \mathrm{CaCl}_{2}$.

curves for $\mathrm{KCl}, \mathrm{MgCl}_{2}$ and $\mathrm{CaCl}_{2}$ are compared with the curve for $\mathrm{NaCl}$, and the results indicate a clear discrimination from $\mathrm{NaCl}$ on the right side. In other words, these results show that irrespective of the concentration of the salty materials, it is possible to identify $\mathrm{NaCl}$ as the main component of table salt as well as $\mathrm{KCl}, \mathrm{MgCl}_{2}$, and $\mathrm{CaCl}_{2}$ as the nigari components. Moreover, if we consider that the orthogonal distance between the curve for $\mathrm{NaCl}$ and the curve for each salty material indicates the difference in taste quality, $\mathrm{KCl}$ has a taste that is closest to that of $\mathrm{NaCl}$, and $\mathrm{CaCl}_{2}$ shows the largest difference in taste.

Next, to determine how $\mathrm{NaCl}, \mathrm{KCl}, \mathrm{MgCl}_{2}$ and $\mathrm{CaCl}_{2}$ included in table salt affect its taste, we measured the samples listed in Table 4 using the two types of saltiness sensor. The results are shown in Fig. 9. The outputs of the mixed solutions of $\mathrm{NaCl}$ and the other nigari components are plotted against the response curves for samples with $\mathrm{NaCl}$ and added nigari components. To make it easier to understand the taste of the different salty materials, we calculated the orthogonal distances between the $\mathrm{NaCl}$ curve and the curves for the nigari components, as shown by the arrows in Fig. 9. These analysis results are shown in Fig. 10. When the vertical axis is zero, the sample has a taste closest to that of $\mathrm{NaCl}$. As the value increases, the taste of the sample differs from that of $\mathrm{NaCl}$. From Fig. 10, when the concentration of $\mathrm{NaCl}$ on the horizontal axis is zero, a comparison of the tastes of the three nigari components shows that $\mathrm{CaCl}_{2}$ has a taste most different from the salty taste of $\mathrm{NaCl}$, indicating that it also can be evaluated as a bitter taste. Furthermore, irrespective of the type of nigari component, increasing the concentration of $\mathrm{NaCl}$ makes each nigari component taste more like $\mathrm{NaCl}$. This result can be empirically considered to have a good correlation with the sensory evaluation scores. Therefore, the values on the vertical axis are described as the bitterness strength using the saltiness sensor. 


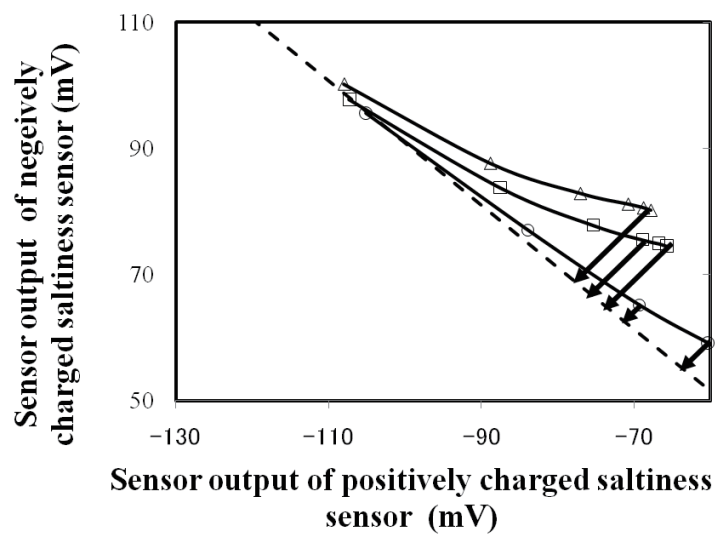

Fig. 9. Response with addition of nigari components (dashed line: $\mathrm{NaCl}, \mathrm{O}: \mathrm{KCl}+\mathrm{NaCl}$, $\left.\square: \mathrm{MgCl}_{2}+\mathrm{NaCl}, \triangle: \mathrm{CaCl}_{2}+\mathrm{NaCl}\right)$.

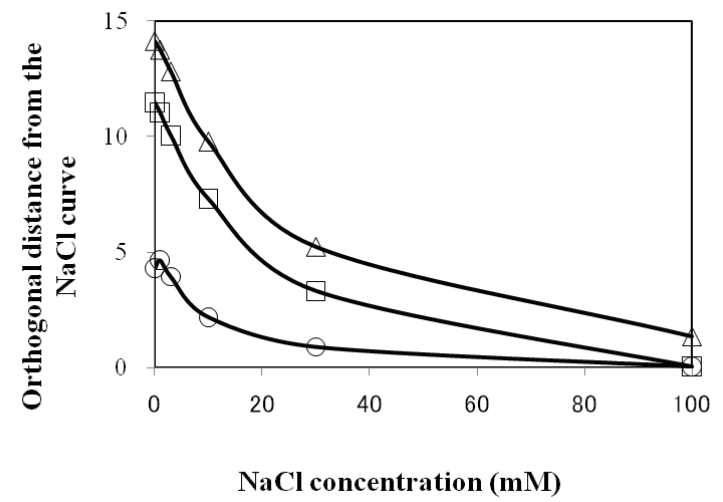

Fig. 10. Changes in orthogonal distance from the $\mathrm{NaCl}$ curve in response with addition of nigari components $\left(\mathrm{O}: \mathrm{KCl}+\mathrm{NaCl}, \square: \mathrm{MgCl}_{2}+\mathrm{NaCl}, \triangle: \mathrm{CaCl}_{2}+\mathrm{NaCl}\right)$.

\subsection{Correlation with sensory evaluations}

From the results in Fig. 10, the response results from the two types of taste show that the taste of table salt varies greatly depending on the included nigari components. To evaluate the validity of these results, sensory evaluation tests were performed for the samples listed in Table 5. Figure 11 shows a scatter plot of the results from Fig. 10 and the sensory evaluation tests. This figure shows that when no $\mathrm{NaCl}$ is added, the bitterness ranking of the three nigari components obtained from the sensor is $\mathrm{CaCl}_{2}>$ $\mathrm{MgCl}_{2}>\mathrm{KCl}$, which is very similar to the human sensory evaluation scores of $\mathrm{CaCl}_{2}$ $\approx \mathrm{MgCl}_{2}>\mathrm{KCl}$. From Fig. 11, at $100 \mathrm{mM} \mathrm{NaCl}$, the data from both the sensory evaluations and sensors indicate that $\mathrm{MgCl}_{2}$ and $\mathrm{KCl}$ are both weakly bitter and only $\mathrm{CaCl}_{2}$ is relatively bitter. We consider that this result is due to the fact that the increasing $\mathrm{NaCl}$ concentration reduces the sensitivity to bitterness, making $\mathrm{MgCl}_{2}$ and $\mathrm{KCl}$ less bitter. 

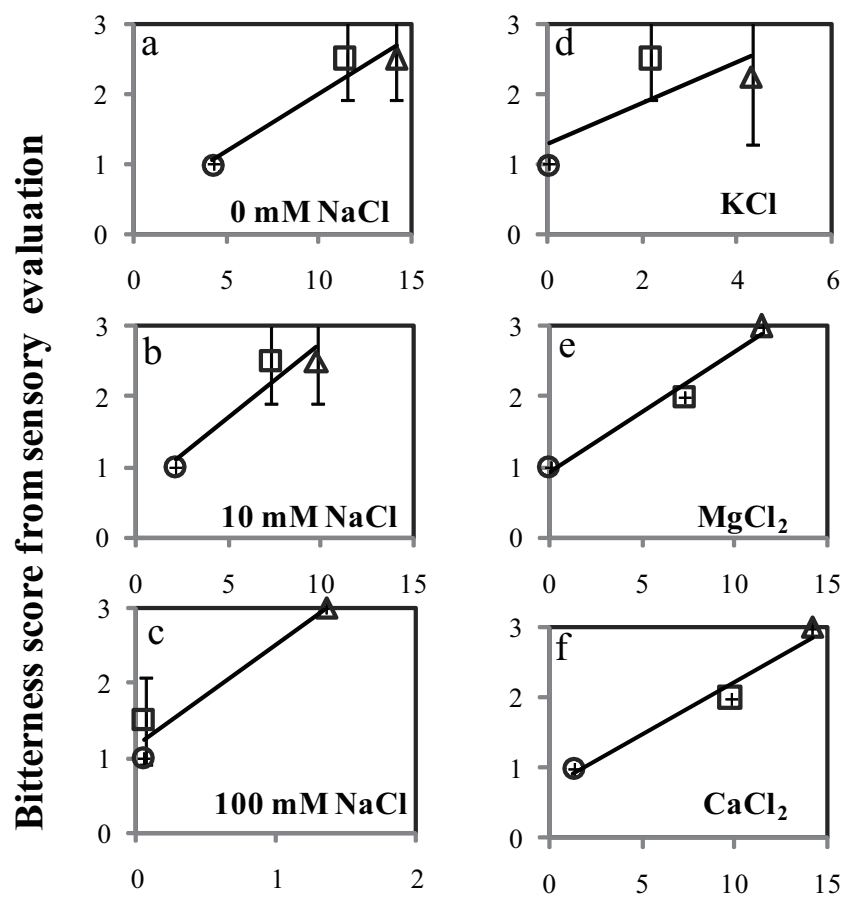

Bitterness strength using the saltiness sensors

Fig. 11. Relationship between bitterness strength from the sensors and sensory evaluation scores with different nigari components (Figs. (a), (b), (c): effect of types of nigari components on the bitterness strength and bitterness score, $\mathrm{O}: \mathrm{KCl}, \square: \mathrm{MgCl}_{2} ; \triangle: \mathrm{CaCl}_{2}$; Figs. (d), (e), (f): effect of $\mathrm{NaCl}$ concentration on the bitterness strength and bitterness score, $\bigcirc: 100 \mathrm{mM} \mathrm{NaCl}, \square: 10 \mathrm{mM}$ $\mathrm{NaCl}, \triangle: 0 \mathrm{mM} \mathrm{NaCl}$ ). Data on horizontal axis are obtained from Fig. 10.

Figure 11(d) shows that when comparing three samples with $\mathrm{NaCl}$ concentrations of 0,10 , and $100 \mathrm{mM}$ at the same $\mathrm{KCl}$ concentration, the sensor data gives a bitterness ranking of $\mathrm{KCl}(0 \mathrm{mM} \mathrm{NaCl})>\mathrm{KCl}(10 \mathrm{mM} \mathrm{NaCl})>\mathrm{KCl}(100 \mathrm{mM} \mathrm{NaCl})$, which is very similar to the human sensory evaluation ranking of $\mathrm{KCl}(0 \mathrm{mM} \mathrm{NaCl}) \approx \mathrm{KCl}(10$ $\mathrm{mM} \mathrm{NaCl})>\mathrm{KCl}(100 \mathrm{mM} \mathrm{NaCl})$. The error bars on the $\mathrm{KCl}(0 \mathrm{mM} \mathrm{NaCl})$ and $\mathrm{KCl}(10$ $\mathrm{mM} \mathrm{NaCl}$ ) sensory evaluations are large, possibly explaining the small difference in taste score. Furthermore, Figs. 11(e) and 11(f) show that increasing the $\mathrm{NaCl}$ concentration reduces the bitterness in both the sensor measurements and sensory evaluations. These results show a high correlation between the results obtained from the sensory evaluations and the sensor outputs. In other words, at a fixed $\mathrm{NaCl}$ concentration, the bitterness ranking is $\mathrm{CaCl}_{2}>\mathrm{MgCl}_{2}>\mathrm{KCl}$, and the bitterness of each bitterness component tends to decrease as $\mathrm{NaCl}$ concentration increases. These results suggest that the two types of saltiness sensor can be used to evaluate both saltiness and other tastes, such as bitterness. 


\section{Conclusions}

This research suggests that it is possible to evaluate the tastes of both $\mathrm{NaCl}$ and other nigari components in table salt by optimizing the sensor composition to improve selectivity for saltiness and performing analysis using the outputs of two salt sensors. Moreover, a comparison with the results of human sensory evaluations shows good agreement, suggesting that the above-described saltiness sensors and analysis methods offer an accurate method for evaluating the various tastes of table salt.

\section{References}

1 N. Matsumoto: The Salt Science Research Foundation Annual Research Report 1991, Physiology Food Science (1991) p.61 (in Japanese).

2 R. Chen, M. Habara and K. Toko: Sens. Materials 15 (2003) 155.

3 K. Toko, R. Chen and M. Habara: Bull. Soc. Sea Water Sci. Jpn. 58 (2004) 57 (in Japanese).

4 K. Toko: Biomimetic Sensor Technology (Cambridge University Press, Cambridge, 2000).

5 K. Toko: Meas. Sci. Technol. 9 (1998) 1919.

6 K. Toko: Sens. Actuators B 64 (2000) 205.

7 M. Watanabe, K. Toko, K. Sato, K. Kina, Y. Takahashi and S. Iiyama: Sens. Materials 10 (1998) 103.

8 H. Ikezaki, Y. Kobayashi, R. Toukubo, Y. Naito, A. Taniguchi and K. Toko: Digest Tech. Papers Transducers '99 (The Institute of Electrical Engineers of Japan, Sendai, 1999) p. 1634.

9 M. Habara and K. Toko: Encyclopedia of Sensors (American Scientific Publishiers, Santa Clarita, 2006) p.107.

10 S. Iiyama, M. Narishige, S. Ezaki and K. Toko: Japanese Sensor Newsletter 12 (1998) 59.

11 K. Hiratani, T. Okada and H. Sugihara: Bull. Chem. Soc. Jpn. 59 (1986) 2015. 